\title{
Government Interventions, Market Integration, and Price Risk in Pakistan's Punjab
}

\author{
TAKASHI KUROSAKI
}

\begin{abstract}
This paper empirically examines the spatial and intertemporal price relations of grains in Pakistan's Punjab. The salient feature of the paper is that quantity variables such as market surplus and government release are incorporated in the price arbitrage model to quantify the effects of government interventions. Regression analysis using three-year crosssection data shows that the farm-gate prices of wheat after harvest are mostly explained by the government support price while those of Basmati paddy have more unexplained variation. This difference could be due to a difference in the price support mechanism. Investigation on intertemporal price relations shows that wholesale wheat prices regularly increase at the rate of storage costs in the first half of a food year, and that the price rise is repressed by the government release in the second half only in a normal year.
\end{abstract}

\section{INTRODUCTION}

The performance of agricultural markets in developing countries has been an important issue in economic development. Their efficient performance provides producers with information on technology and consumers' preferences, thereby inducing dynamic production responses to changing market conditions. This dynamics is an indispensable part of economic development. From individual households' viewpoint, the efficient performance reduces price risk since it prevents unnecessary price volatility. Since numerous developing countries are currently promoting marketing liberalisation policies, the issue of market performance and price relations is attracting the attention of academic and policy circles. Whether the reforms will have the expected effects depends on the performance of each market involved.

This paper empirically investigates the performance of grain markets in the Punjab province of Pakistan. The primary objectives of the paper are to analyse market price relations and to test for the effects of government interventions on them. The analysis focuses on wheat, the staple food of the nation, supplemented by an analysis on Basmati rice, a major export commodity of Pakistan, for purposes of comparison. Most of the existing studies on market performance in Pakistan are descriptive, except for the work by Faiz Mohammad, who analyses market prices using a simple econometric

Takashi Kurosaki is based at the Institute of Developing Economies, Tokyo, Japan.

Author's Note: I would like to thank Bob Baulch, S. Hirashima, Koji Yamazaki, H. Yonekura, and the anonymous referees of this journal for helpful comments on an earlier version of this paper. The usual disclaimer applies. 
model [Mohammad (1983, 1985); Mohammad and Tahir (1988)]. This study extends the existing literature by incorporating quantity variables, such as market surplus or government release, to explain the relations of prices realised in private marketing channels. It will be shown that the farm-gate prices of wheat after harvest are explained mostly by the government support price while the effects of government wheat release on the market prices in lean months vary depending on the characteristics of each year.

The paper is organised as follows. In Section 2, the analytical framework is explained briefly. The empirical strategy in this study is to go back to the arbitrage condition, which needs to be satisfied for prices in a spatial or intertemporal competitive equilibrium. Following Section 3 that describes the study area and data, Section 4 investigates the spatial relationship between government support prices and farm-gate prices after harvest. Section 5 tests for the effects of government wheat release on intertemporal price changes. Section 6 concludes the paper with a summary and policy implications.

\section{METHODOLOGY}

There is a large and expanding literature on market performance in developing countries. Starting with the classic works by Lele (1971) and Jones (1972), the literature now covers a wide range of countries and a number of sophisticated methods [e.g. Ravallion (1986); Hayami and Kawagoe (1993); Baulch (1995); Goletti, Ahmed, and Farid (1995)]. As is shown in Baulch (1996), most of the recent, sophisticated timeseries models have failed to incorporate the non-linearity caused by the existence of transaction costs and non-continuous trade flows. Therefore, instead of applying these time-series methods, this paper goes back to the arbitrage condition for prices in a spatial or intertemporal competitive equilibrium [Takayama and Judge (1971); William and Wright (1991)] that forms the basis of the recent models.

Arbitrage (in)equality is satisfied when either of the following two is observed. First, if transactions occur between two states of a commodity, the price difference should equal the transaction costs; the difference should not be larger than the transaction costs, because it implies an arbitrage opportunity. Second, if transactions do not occur, the price difference should be smaller than or equal to the transaction costs. The transactions between two states include spatial (transportation/trade), intertemporal (storage), or vertical (processing) transactions. When the arbitrage condition holds as an equality, prices in the corresponding two markets are said to be integrated spatially, intertemporally, or vertically.

The arbitrage condition prevents unnecessarily volatile movement of prices. It transmits price signals smoothly from urban food-deficit to rural food-surplus areas or from a food-deficit to food-surplus period. In this sense, the condition is necessary for the efficient performance of markets. A well-integrated market system is the key to an efficient allocation of productive resources. It also contributes to household and 
regional food security. When the arbitrage condition is satisfied, price risk is reduced because a local shock is transmitted to integrated markets.

\section{STUDY AREA AND DATA DESCRIPTION}

\section{Wheat Marketing}

Wheat is the most important source of calory intake in Pakistani diet. Although most farmers grow wheat and its per-acre yield has increased significantly during the last four decades, Pakistan has not yet achieved self-sufficiency. In recent years, one to two million tonnes of wheat are imported to supplement the domestic production of approximately 15 million tonnes.

In the current system of wheat marketing, the public sector and private traders coexist. Although deregulation policies in wheat marketing have been implemented since the mid-1980s, public interventions have remained important. ${ }^{1}$ The government procures wheat from producers directly; it releases wheat flour to consumers directly through utility stores owned by a government corporation or indirectly through private markets. The price of wheat through this route is fixed by the federal government panterritorially: the provincial food departments and the Pakistan Agricultural Storage and Services Corporation (PASSCO) ${ }^{2}$ procure wheat in harvest months at the "support" price; the provincial food departments release wheat flour in lean months at the "issue" price.

At the same time, the private sector is allowed to market wheat with free prices. Instead of bringing wheat directly to public procurement centres, most farmers sell to middlemen such as village shopkeepers and beoparis (village brokers). These traders sell wheat to the public procurement centres or to other private traders. Primary wholesale markets (mandis) are well-developed in Pakistan, especially in the Punjab. Farmers and middlemen bring wheat to these markets and sell through arhtis (commission agents) who are registered in the Market Committee [Government of Punjab (1991)]. The arhtis collect wheat from growers and primary middlemen and deliver it to millers and wholesalers.

At the national level, the public wheat procurement accounts for about four million tonnes or just below 30 percent of the total production. Assuming the market surplus share of wheat to be in the range of 40 to 45 percent [Cornelisse and Naqvi (1987, 1989)], approximately one-third of the total marketed wheat does not enter the public marketing chain at all. A substantial portion of the remaining two-thirds also

${ }^{1}$ The deregulation policies include the lifting of the ban on the private inter-provincial trade of wheat and wheat de-rationing. See Cornelisse and Naqvi (1987, 1989); Alderman, Chaudhry, and Garcia (1988); Pinckney (1989) and Ender (1992) for references.

${ }^{2}$ The PASSCO is a parastatal agency that procures and stores wheat for inter-provincial distribution. Among the four provinces of Pakistan, the Punjab is the only surplus province. The PASSCO is responsible for the provision of wheat to the deficit provinces. 
enters the private marketing chain because the government releases wheat stock to wholesale markets to stabilise prices in lean months. This portion is much larger than the portion released to consumers directly through utility stores [Pinckney (1989); Ender (1992)].

This institutional framework implies two points where government interventions potentially affect prices realised in the private marketing chain. The first point is the effect of government procurement on farm-gate prices in harvest months (Section 4). The second is the effect of government release on market prices in lean months (Section 5).

\section{Basmati Marketing}

Basmati paddy/rice marketing has a different institutional framework since paddy is husked and cleaned in rice mills. Basmati rice is produced in the Punjab and is one of the most important export commodities of Pakistan. Until 1987/88, the export of Basmati rice was a public monopoly. A parastatal corporation, the Rice Export Corporation of Pakistan (RECP) procured cleaned rice from private rice millers and middlemen at the support price fixed by the federal government. Since 1987/88, deregulation has been proceeding rather well in rice export. Especially, fiscal year 1990-91 witnessed a dramatic change, when the share of the private sector in Basmati export increased rapidly from almost nil to more than one-third.

The federal government announces the support price for paddy in the same manner as wheat. The PASSCO has responsibility for supporting paddy prices. However, the quantity of Basmati paddy procured by the PASSCO was less than 2 percent of the total production. The price of Basmati paddy is supported indirectly through the procurement of cleaned rice by the RECP. Between growers and millers, various middlemen exist: growers may sell through commission agents (arhtis) or village brokers (beoparis) on a commission basis; sell to the agents of rice millers; or sell to village traders. The arhtis' role is as important in this trade as in wheat marketing.

\section{Data}

Three sources of data are used in the analysis. ${ }^{3}$ First, to investigate the price behaviour of wheat and Basmati paddy at farm gate, three-year cross-section data on household production and consumption in the rice-wheat zone of Pakistan's Punjab are used in Section 4. The initial data were collected from five villages in the Sheikhupura district by the Punjab Economic Research Institute (PERI), Lahore. ${ }^{4}$ The data set

${ }^{3}$ Data sets used in the regressions are available from the author on request.

${ }^{4}$ The general sampling procedure and the aggregated results for each year are reported in Haque and Saleem (1990); Cheema and Saleem (1993); and Saleem and Cheema (1993). Thanks are due to Dr Muhammad Jameel Khan, Director, PERI, for access to the surveys. See Kurosaki (1995) for an analysis of these sample observations, using a non-separable household model. 
includes 97 household observations each for three fiscal years from 1988-89 through 1990-91, a period corresponding to 1989-90 - 1991-92 food years. ${ }^{5}$

Second, weekly and monthly prices in major wholesale markets are available from published sources. Wholesale markets in the Punjab are regulated by provincial laws and regulations including the one that obliges the Market Committee to report prices [Government of Punjab (1991)]. In Section 5, monthly prices of wheat in ten major wholesale markets in the province (Lahore, Faisalabad, Rawalpindi, Multan, Gujranwala, Sialkot, Sargodha, Okara, Sahiwal, and Sheikhupura) during 1989-90 to 1991-92 food years are used. The data source is Monthly Statistical Bulletin issued by the Federal Bureau of Statistics, Karachi.

Third, the quantity of wheat and Basmati procured by public agencies and the quantity of wheat released by the Punjab Food Department are obtained from each agency involved. District level data in each month for the period 1989-90 to 1991-92 food years are used in the analysis of wheat release in Section 5 .

\section{EFFECTS OF GOVERNMENT SUPPORT PRICES ON FARM-GATE PRICES AFTER HARVEST}

This section investigates the spatial relations of prices just after harvest, using the three-year cross-section data. The data include information on the farm-gate prices of wheat and Basmati paddy after harvest. Most sample households sold these commodities immediately after harvest in the village they lived in. Enumerators recorded the prices received by farmers for the most representative transaction. Some farmers brought the commodities directly to the government procurement centre or to the town mandi. In these cases, transportation costs were adjusted to obtain the farmgate price. Let $P_{f}$ denote the farm-gate price recorded in this way.

\section{Analytical and Empirical Models}

Since $P_{f}$ is the price observed in actual transactions in the villages, the task is to test whether the arbitrage equality holds or not between the farm-gate price and the price in the town $\left(P^{*}\right)$. Denoting per-unit transportation costs from the farm to the town as $T$, the arbitrage relation is expressed algebraically as

$$
\begin{array}{lllllll}
P^{*}=P_{f}+T & \ldots & \ldots & \ldots & \ldots & \ldots & \ldots
\end{array}
$$

Assuming absolute market margins, the following simple model of transportation cost is used in the empirical investigation.

$$
T=\beta_{1} D+\beta_{2} 1 / Q \quad \ldots \quad \ldots \quad \ldots \quad \ldots \quad \ldots \quad \ldots
$$

${ }^{5} \mathrm{~A}$ food year corresponds to a period from May to April. This implies a one-year lag in wheat accounting. For example, the wheat crop harvested in April-May 1990 is counted as produce of the 1989-90 fiscal year but as foodgrain for the 1990-91 food year. 
(adjusted $R^{2}=0.99$ ). Second, coefficient estimates for transportation costs are of the correct sign. However, the coefficient on $1 / Q$ is not statistically significant. Therefore, the model is re-estimated without the variable $1 / Q$ ("Model B"). Third, the coefficient on $P_{p}$ is 0.95 , reasonably close to unity, which is the theoretical prediction in (1). ${ }^{7}$

The regression results for wheat show that the farm-gate price after harvest is explained almost wholly by the government support price and the distance to the town. Recall that most sample households did not bring wheat to the procurement centre but sold it to private middlemen in the villages. Even in these cases, the farm-gate prices are integrated efficiently with the support price in the town. Active competition among middlemen and substantial procurement by the government in the town are responsible for the efficient performance.

A similar regression model is estimated for Basmati paddy (Table 2). First, adjusted $R^{2}$ is very low, showing that a large portion of price variation is not explained by the support price, the distance to the town, and the quantity marketed. Second, both

Table 2

2SLS Estimation Results for Basmati Paddy Farm-gate Prices

\begin{tabular}{lccc}
\hline $\begin{array}{c}\text { Explanatory Variables } \\
\text { (Units) }\end{array}$ & Model A & Model B & $\begin{array}{l}\text { Statistics of } \\
\text { Exp. Var. }\end{array}$ \\
\hline Intercept & $89.44^{* * *}$ & $89.13^{* * *}$ & \\
& $(23.85)$ & $(23.40)$ & \\
$P_{p}(\mathrm{Rs} / 40 \mathrm{~kg})$ & $0.324^{* * *}$ & $0.320^{* * *}$ & $142.8 \#$ \\
& $(12.40)$ & $(12.07)$ & {$[6.18]$} \\
$D(\mathrm{~km})$ & $-0.157^{* * *}$ & $-0.133^{* * *}$ & 9.44 \\
& $(-4.055)$ & $(-3.465)$ & {$[4.26]$} \\
$1 / Q(1 / 40 \mathrm{~kg})$ & $-30.851^{* * *}$ & & 0.0217 \\
& $(-3.023)$ & & {$[0.0307]$} \\
\hline Adjusted $R^{2}$ & 0.376 & 0.354 & \\
\hline
\end{tabular}

Notes: (1), (2), (3) see Table 1.

(4) Dependent variable is $P_{p}$ whose mean is 133.50 and standard deviation is 3.44 .

(5) The number of observations is 287.

\# $P_{p}$ (support price for Basmati paddy) was 135, 143.5, and $150 \mathrm{Rs} / 40 \mathrm{~kg}$ in 1988-89, 1989-90, and 1990-91 respectively.

${ }^{7}$ Strictly speaking, the Wald test rejects the null hypothesis that $\alpha_{2}=1$ at 1 percent level. However, $P^{*}$ in the theoretical model in (1) should be a price in the town net of marketing costs that are not incurred in transactions in villages. These marketing costs include, for example, commission fee, facility usage fee, the opportunity cost of waiting in front of the procurement centre, etc. If the variable $P_{p}$ in (3) is replaced by the support price discounted by 3 percent, the estimate for $\alpha_{2}$ becomes much closer to unity and $\alpha_{2}=1$ is no longer rejected. In this sense, the coefficient estimate of 0.95 for $\alpha_{2}$ is "reasonably" close to unity. 
coefficient estimates on $D$ and $1 / Q$ are negative and statistically significant, suggesting the existence of scale economy in transportation. The contrasting results for the coefficient on $1 / Q$ between wheat and Basmati could be due to a difference in the nature of the two commodities. Wheat is a staple food for which village demand exists even for a smaller quantity. On the other hand, since Basmati paddy is a cash crop in the area and has to be sent to rice mills for processing, a larger lot in a village has a natural advantage in transportation. Third, the coefficient on $P_{p}$ is 0.32 , significantly smaller than unity, which is the theoretical prediction of perfect arbitrage.

The contrast is striking: the farm-gate price of wheat is explained well by the support price and the distance, with the coefficient on the support price close to unity; the farm-gate price of Basmati paddy is not explained well by these variables and the coefficient on the support price is not close to unity.

\section{Implications}

Three implications could be derived from the above findings. First, the effects of government support prices on farm-gate prices differ from commodity to commodity, depending on the way the support price policy is implemented. A public procurement centre for wheat is opened in the town every year with substantial procurement, resulting in high integration of farm-gate prices with town market prices of wheat; the direct procurement of Basmati paddy by the public sector is negligible, resulting in nonsmooth transmission of procurement prices to the farm gate. When the effects of a revision in support prices are discussed, the exact way in which the support prices affect the prices received by farmers needs to be considered.

Second, from individual household's viewpoint, ex ante price risk is smaller for wheat than for Basmati paddy. The regression results show that wheat price risk at the time of wheat planting is minimal if the support price is announced by that time. Officially, the support price for wheat is to be announced in early October when wheat sowing begins. However, the announcement is often delayed or revised later. Upward price revisions happened in the 1990-91, 1993-94, and 1995-96 fiscal years after wheat was sown. Reliable and timely announcement of wheat support price is desirable, from farmers' viewpoint, so as to reduce uncertainty.

Third, when public procurement is implemented well, as in wheat in the study area, the government support price is transmitted efficiently to village markets. Even when farmers do not sell at the procurement centre, competition among middlemen forces the farm-gate price at the support price minus transportation costs. In other words, the rural marketing network of private middlemen contributes to the spatial integration of wheat prices. Obviously, further research is needed to generalise this result for the whole province or for Pakistan. Nevertheless, the existing literature on the spatial integration of wholesale markets in Pakistan seems to offer reasons to expect the relations to hold to some extent. Studies by Faiz Mohammad (1983, 1985), who 
examined market price correlations, and by Kurosaki (1994), who applied Ravallion's model of short-run and long-run integration, all support the view that most wholesale markets in Pakistan's Punjab are integrated spatially.

\section{EFFECTS OF GOVERNMENT RELEASE ON THE SEASONALITY OF WHOLESALE WHEAT PRICES}

This section focuses on how the public release of wheat to markets in lean months affects intertemporal price changes. The data on monthly wholesale prices in ten major markets in the Punjab and the district-wise data on the quantity of wheat release in the province are used in this section (Section 3).

\section{Analytical Framework}

Arbitrage (in)equality for the intertemporal transactions (i.e., storage) is said to hold when either of the following relations is satisfied between the current price $\left(P_{t}\right)$ and the immediate future price $\left(P_{t+1}\right)$ [Williams and Wright (1991)]:

$$
\begin{array}{lllll}
\left(P_{t}+C\right)(1+r)=E_{t}\left[P_{t+1}\right], & S_{t}>0 & \ldots & \ldots & \ldots \\
\left(P_{t}+C\right)(1+r) \geq E_{t}\left[P_{t+1}\right], & S_{t}=0 & \ldots & \ldots & \ldots
\end{array}
$$

where $C$ is physical storage costs per period, $r$ is the interest rate, $E_{t}[.$.$] is an$ expectation operator at $t$, and $S_{t}$ is the quantity of private storage carried over from period $t$ to $t+1$.

In the study area, the provincial government releases wheat to markets in the lean months at a fixed issue price (Section 3). The difference between the issue price and the procurement price does not cover all the storage costs from harvest months to the end of a food year [Pinckney (1989); Ender (1992)]. Two extreme cases are useful to stylise private storage activities in this context.

First, if wheat released by the government and wheat stored by the private sector are perfect substitutes, and if the public release is continued as long as market demand exists at the issue price, ${ }^{8}$ then the private sector stores only in the early months when it expects zero public release (the equality in (4a) holds). Once the private sector expects positive public release, no private storage is carried over since it inevitably incurs a loss (the inequality in (4b) holds). This is a situation with full government effects.

On the contrary, if wheat released by the government and wheat stored by the private sector form two segmented markets, or if the public release is cut off with probability one at a level lower than the market demand at the issue price, then market demand for private storage continues to exist even when the government releases wheat. Therefore, market prices continue to rise regularly throughout a food year, following the equality in (4a). This is a situation with no government effects.

\footnotetext{
${ }^{8}$ This is the official stance of the government release policy [Pinckney (1989)].
} 
The reality is expected to lie between these two cases. In early months when the quantity of public release is small, market prices rise in a way close to the equality in (4a). The market is dominated by privately-stored wheat. As the public release increases in lean months, private storage begins to be crowded out by publicly-stored wheat, but not completely. Figure 1 casually supports this hypothesis. From May to October, market prices rise regularly; from October to April, intertemporal price relations vary from year to year.

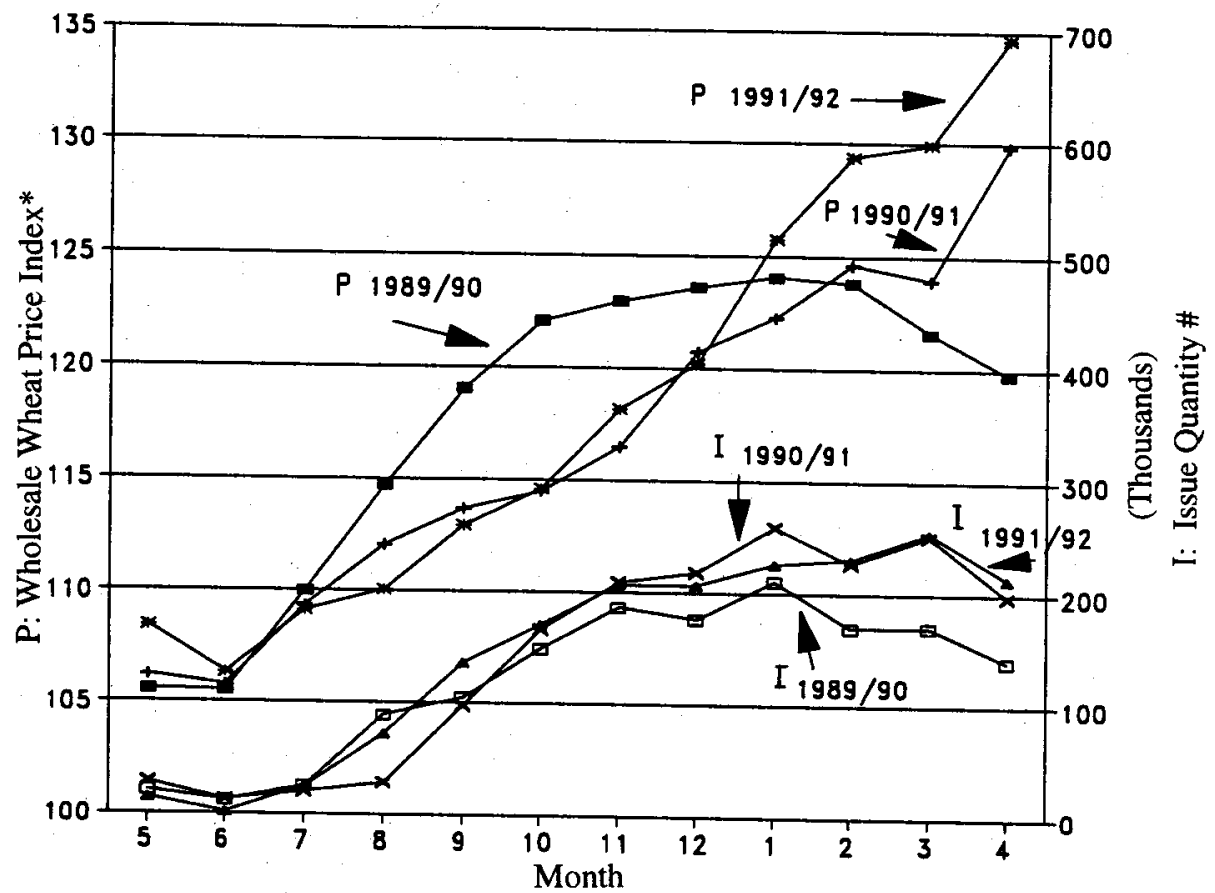

Fig. 1. Seasonality of Wheat Wholesale Prices and Public Wheat Release.

Notes: * The wholesale wheat price index is defined as the average of wholesale wheat price indices in the ten wholesale markets. The wholesale wheat price index in each market in each year is an index with government support price in the year as 100 .

\# The issue quantity is defined as the sum of government release of wheat in the ten markets in each month.

Unit is tonnes. 


\section{Empirical Model and Estimation Results}

Based on the theoretical model in (4), this paper proposes the following empirical model, which allows the impact of public release of wheat to be estimated simultaneously with the seasonal price patterns:

$$
P_{t}=P_{t-1} \cdot \exp \left(\alpha+\beta D_{g, t}\right)+u_{t} \quad \ldots \quad \ldots \quad \ldots \quad \ldots
$$

where $\alpha$ and $\beta$ are parameters to be estimated, $D_{g}$ is a dummy variable for government wheat release, and $u$ is an error term with zero mean. $\alpha$ is an estimate for the rate of total storage costs, ${ }^{9}$ which should have a positive value. $\beta$ represents the effects of government release on price changes. If it is zero, the government wheat release has no effect on market prices; if it is negative, price rises are repressed by government release; and if $\beta$ completely offsets the total storage costs $(\alpha+\beta=0)$, the government release at the issue price stabilises market prices completely, a situation with full government effects.

$D_{g, t}$ is defined as a threshold dummy variable that takes the value of unity when per-capita release in a district in month $t$ exceeds some critical level and takes the value of zero otherwise. This is to grasp the effects of an active government intervention into private markets, which occur in the late months of a food year (Figure 1).

The model in (5) is estimated by a maximum likelihood (ML) method assuming the normality of $u$. Table 3 gives results in which the threshold level for $D_{g, t}$ is chosen at $2.5 \mathrm{~kg}$ per capita. ${ }^{10}$ In Model A, $\alpha$ and $\beta$ are allowed to vary from year to year. Since the null hypothesis that $\alpha$ is constant over years is not rejected at 10 percent by the Wald test, estimation results with the restriction of constant $\alpha$ are reported as well (Model B).

According to the results of Model B, $\alpha$ is estimated at 1.7 percent per month, or 21 percent per year. This is the estimate for total storage costs. According to State Bank of Pakistan Bulletin, market interest rates during the study period were about 11 percent (the average lending rate from commercial banks to the private sector) or 12 to 12.5 percent (the short-term lending rate from the Agricultural Development Bank of

${ }^{9}$ This approximation is more precise when physical storage $\operatorname{cost} C$ is proportional to the initial value of the commodity. By inserting $C=c P_{t}$ in the left-hand side of the equality in (4a),

$$
\begin{gathered}
\left(P_{t}+C\right)(1+r)=P_{t}(1+c)(1+r)=P_{t} \cdot \exp (\alpha)=E_{t}\left[P_{t+1}\right] \\
\therefore \alpha \approx c+r
\end{gathered}
$$

The physical storage costs include storage loss, rental fee for storage space, chemicals costs, etc. Among them, the storage loss, which is expected to be the most important in the conditions in Pakistan, is likely to be proportional to the initial quantity. Therefore, the approximation of $C$ by $c P_{t}$ might be justifiable.

${ }^{10}$ In the initial regression, $\alpha$ and $\beta$ are allowed to vary from market to market and from year to year. However, since differences among markets are not statistically significant (a finding consistent with spatially integrated markets), estimation results without location dummies are reported in Table 3. 
Table 3

ML Estimation Results for Intertemporal Wheat Price Relations (Asymptotic $t$-statistics are in the parenthesis)

\begin{tabular}{lcccc}
\hline Parameter & \multicolumn{2}{c}{ Model A } & \multicolumn{2}{c}{ Model B } \\
\hline$\alpha_{1989-90}$ & 0.0208 & $(3.676)^{* * *}$ & & \\
$\alpha_{1990-91}$ & 0.0175 & $(3.371)^{* * *}$ & & \\
$\alpha_{1991-92}$ & 0.0139 & $(3.296)^{* * *}$ & & \\
$\alpha_{\text {common }}$ & & & 0.0167 & $(5.882)^{* *}$ \\
& & & & $*$ \\
$\beta_{1989-90}$ & -0.0140 & $(-1.872)^{*}$ & -0.0099 & $(-1.756)^{*}$ \\
$\beta_{1990-91}$ & -0.0043 & $(-0.633)$ & -0.0035 & $(-0.667)$ \\
$\beta_{1991-92}$ & 0.0076 & $(1.334)$ & 0.0048 & $(1.010)$ \\
\hline$R^{2}$ & \multicolumn{5}{c}{0.946} & \multicolumn{2}{c}{0.946} \\
Log likelihood & \multicolumn{2}{c}{-820.440} & -820.925 \\
\hline
\end{tabular}

Notes: (1) Dependent variable is $P_{t}$ whose mean is 114.8 and standard deviation is 16.0 .

(2) The number of observations is 300 (=10 markets $\times 3$ years $\times 10$ months). Each year in each market has ten months to avoid the discontinuity of wheat in a food year. The model in (5) is estimated for $P_{t}$ with $t=$ June to March.

(3) In each year with 100 observations, the government release dummy $\left(D_{g}\right)$ takes the value of unity in 53 cases (1989-90), 54 cases (1990-91) and 51 cases (1991-92).

(4) *significant at 10 percent level; **significant at 5 ; ***significant at 1 percent level (twosided test).

Pakistan). A reliable study estimated the physical storage loss at around 7 percent per year [Pinckney (1989)]. Therefore, the estimate for total storage costs at 21 percent seems reasonable, attributable to interests (12 percent), storage loss (7 percent), and other physical storage costs (2 percent).

Parameter estimate for $\beta$ is significantly negative in $1989-90$ but it is not significant in the next two years. Therefore, the government release repressed price rises in 1989-90 but its effects were not discernible in 1990-91 and 1991-92. On the other hand, the null hypothesis that $\alpha+\beta=0$ for $1989-90$ was rejected at 10 percent by the Wald test for both models. This suggests that even in the year 1989-90 when the government release did repress market price rises, the prices did not stay at the issue price but increased at a repressed rate.

\section{Implications}

Several interpretations for these findings could be given. The first is the way the government releases wheat. In spite of the official policy of unlimited release at the issue price, the government actually follows its annual schedule for wheat release with 
some flexibility to adjust the exact quantity to the ongoing market situation. Therefore, the realised quantity of government release is likely to be short of the market demand but able to meet its substantial portion. From private traders' viewpoint, there is uncertainty regarding how sufficient the government release in the next month will be. Because of this uncertainty, the private sector has an incentive to store wheat even in lean months.

Second, government-released and privately-stored wheat are neither perfect substitutes nor segmented commodities. The biggest reason for this imperfect substitutability is that a major portion of the government-released wheat comes to the market as wheat flour. Demand for wheat comprises direct demand for consumption and derived demand for storage. The first demand can be met by the governmentreleased wheat flour, but the storage demand cannot be met by the flour. In addition to that, a difference in quality might exist between government-released and privatelystored wheat.

These interpretations are helpful in explaining the difference among years. Judging from the long-term trend, the national wheat production in 1988-89 was close to normal while that in 1989-90 and 1990-91 was below normal in each year. In a food year after a bad domestic harvest, the uncertainty regarding government release increases. The substitutability between government-released and privately-stored wheat decreases because the premium for storability increases. Therefore, the effects of government release on price changes become insignificant in a bad harvest year, as in the regression results for 1990-91 and 1991-92. Since the actual quantities of government wheat release in these two years were not below the quantity in 1989-90 (Figure 1), the observed price relations are hard to justify ex post. Nevertheless, it might have been individually rational ex ante for private traders to keep storage, preparing for the possibility of a significant decrease in the quantity of government release.

\section{CONCLUDING REMARKS}

This paper examined the price relations of grains in Pakistan's Punjab and the effects of government interventions on them. Investigation on spatial price relations after harvest found that the farm-gate prices of wheat were mostly explained by the support price whereas those of Basmati paddy had more unexplained variation. This paper suggested that the difference was due to a difference in the price support mechanism. In the second empirical investigation, intertemporal price relations and the effects of public wheat release on them were examined using wholesale market prices. It was found that wheat prices regularly increased at the rate of storage costs in the first half of a food year, but the price rise was repressed by the government release in the second half in a normal year.

To generalise these findings, the price relations in the first half of a food year after harvest were close to those predicted by the arbitrage condition. In the sense that 
the arbitrage condition is necessary for a competitive equilibrium, the price relations were fairly efficient. Prices were found to be integrated spatially and intertemporally so that their excess volatility was prevented. It was suggested that the efficiency was achieved by competition among private traders who are engaged in trade and storage. On the other hand, the effects of government wheat release on intertemporal price relations in lean months varied from year to year, the variation not explained by a simple arbitrage argument. In a year after a bad harvest, government-released and privately-stored wheat might become less substitutable; thus, from private traders' viewpoint, uncertainty increases. It is left for further research to examine whether this is a distortion created by government interventions in efficient private marketing or a reflection of private traders' inability to efficiently deal with the uncertainty inherent in lean months.

Four implications, relevant to Pakistan's agricultural marketing policies, can be derived from these findings. First, private traders in Pakistan are capable of achieving efficient price relations so that a marginal decrease in public interventions in the current set-up could not lead to exploitation by traders. In this sense, the findings support the current marketing policies of deregulation and liberalisation in Pakistan.

Second, the above point should be read with a caution. Empirical findings have suggested a possibility of inefficiency in private marketing chains in lean months. The implication is against a radical decrease in public interventions in wheat marketing. Considering these two implications, for example, an attempt to bring the price differential between the support and the issue prices closer to the opportunity cost of public storage would increase the efficiency of overall wheat marketing.

Third, reliable implementation of government marketing policies would enhance the efficiency of private marketing and farm production. For example, reliable and timely announcement of wheat support price is desirable to reduce uncertainty from farmers' viewpoint; formulation of more concrete and reliable policy rules in implementing the wheat procurement and release policies, including quick provision of detailed market information to private traders, could stabilise grain prices effectively.

Fourth, Basmati paddy prices at the farm level had more unexplained variation than wheat prices. Whether the unexplained variation can be explained efficiently by a difference in marketing methods and in opportunity costs of production factors for farmers and middlemen is a very interesting and promising avenue for future research, ${ }^{11}$ for which more detailed information on marketing is required. Considering the transient nature of Basmati marketing in the study period (Section 3), it would be safe to expect liberalisation policies which encourage competition among private traders and millers to contribute to better performance of local paddy markets.

As a final remark, three policy implications are given for agricultural marketing research in developing countries in general. First, even in Pakistan’s Punjab with a long

${ }^{11}$ Hayami and Kawagoe (1993) explored this direction for the case of upland crops in Indonesia. 
history of private traders, how close the price relations are to the ideal, efficient relations varies from commodity to commodity and period to period. Representative analysis or average-based analysis might conceal these differences. Second, when private marketing channels coexist with government procurement and release, it might not be relevant to use government procurement price as the producer price and government release price as the consumer price. Prices in the private channels reflect the ongoing market conditions including government interventions. The relations of these prices need to be analysed comprehensively. Finally, a marketing reform has a different impact depending on the location and timing of its implementation. Space and time should be incorporated explicitly in the analytical model; quantity variables, such as quantity traded or government release, should be included explicitly in the empirical model.

\section{REFERENCES}

Alderman, H., M. G. Chaudhry, and M. Garcia (1988) Household Food Security in Pakistan: The Ration Shop System. Washington, D. C.: International Food Policy Research Institute. (Working Papers on Food Subsidies, Number 4.)

Baulch, Bob (1995) Transfer Costs, Spatial Arbitrage and Testing Food Market Integration. Sussex: Institute of Development Studies. (IDS Working Paper 20.)

Baulch, Bob (1996) There's Still Madness in the Method: Testing for Food Market Integration Revisited. Sussex: Institute of Development Studies. (IDS Working Paper 28.)

Cheema, M. A., and M. A. Saleem (1993) Farm Accounts, Family Budgets of Rural Families, and Cost of Production of Major Crops in Punjab: 1989-90. Lahore: Punjab Economic Research Institute.

Cornelisse, Peter A., and S. N. H. Naqvi (1987) The Wheat-marketing Activity in Pakistan. Islamabad: Pakistan Institute of Development Economics.

Cornelisse, Peter A., and S. N. H. Naqvi (1989) An Appraisal of Wheat Market Policy in Pakistan. World Development 17: 409-419.

Ender, Gary (1992) Post-rationing Wheat Policy in Pakistan: Issues and Opportunities: Agricultural Policy Analysis Project, Phase II (APAP II). Bethesda, MD: APAP II Project Office. (Collaborative Research Report No. 345.)

Goletti, F., R. Ahmed, and N. Farid (1995) Structural Determinants of Market Integration: The Case of Rice Markets in Bangladesh. Developing Economies 33: 185-202.

Haque, M., and M. A. Saleem (1990) Farm Accounts, Family Budgets of Rural Families, and Cost of Production of Major Crops in Punjab: 1988-89. Lahore: Punjab Economic Research Institute.

Hayami, Yujiro, and T. Kawagoe (1993) The Agrarian Origins of Commerce and Industry: A Study of Peasant Marketing in Indonesia. New York: St. Martin's Press. 
Jones, William O. (1972) Marketing Staple Food Crops in Tropical Africa. Cornell: Cornell University Press.

Kurosaki, Takashi (1994) An Econometric Analysis of Price Relations and the Effects of Government Intervention: The Case of Wheat in the Pakistan Punjab. Ajia Keizai 35:10 31-63 (In Japanese).

Kurosaki, Takashi (1995) Risk Attitudes, Consumption Preferences, and Crop Choices in the Pakistan Punjab. Ph. D. Dissertation, Stanford University.

Lele, Uma (1971) Food Marketing in India: Private Performance and Public Policy. Cornell: Cornell University Press.

Mohammad, Faiz (1983) An Analysis of the Structure and Performance of Agricultural Markets in Pakistan. Ph. D. Dissertation, Simon Fraser University.

Mohammad, Faiz (1985) Farm Prices and the Green Revolution: Some Reflections on the Performance of Private Agricultural Markets in Pakistan. The Pakistan Development Review 24:2 104-23.

Mohammad, Faiz, and S. Tahir (1988) Agricultural Prices in Pakistan: Multi-market Analysis. The Pakistan Development Review 27: 577-592.

Pinckney, Thomas C. (1989) The Demand for Public Storage of Wheat in Pakistan. Washington, D. C.: International Food Policy Research Institute. (IFPRI Research Report No. 77.)

Punjab, Government of (1991) The Punjab Agricultural Produce Markets Ordinance (XXIII of 1978), the Punjab Agricultural Produce Markets (General) Rules, 1979, and the Punjab Agricultural Produce Markets (Market Committees Provincial Fund) Rules, 1980. Lahore: Agriculture Department, Directorate of Economics and Marketing.

Ravallion, Martin (1986) Testing Market Integration. American Journal of Agricultural Economics 68: 102-109.

Saleem, M. A., and M. A. Cheema (1993) Farm Accounts, Family Budgets of Rural Families, and Cost of Production of Major Crops in Punjab: 1990-91. Lahore: Punjab Economic Research Institute.

Takayama, Akira, and G. Judge (1971) Spatial and Temporal Price and Allocation Models. Amsterdam: North-Holland Publishing.

Williams, Jeffrey, and B. D. Wright (1991) Storage and Commodity Markets. Cambridge: Cambridge University Press. 